\title{
Эффекты легирования сульфида свинца серебром на решеточных и оптических свойствах твердых растворов $\mathrm{Pb}_{1-x} \mathrm{Ag}_{x} \mathrm{~S}$
}

\author{
(C) С.И. Садовников \\ Институт химии твердого тела Уральского отделения Российской академии наук, \\ 620990 Екатеринбург, Россия \\ E-mail: sadovnikov@ihim.uran.ru
}

Поступила в Редакцию 27 сентября 2018 г. В окончательной редакции 8 июля 2019 г. Принята к публикации 10 июля 2019 г.

\begin{abstract}
Получены однофазные ограниченные кубические твердые растворы $\mathrm{Pb}_{1-x} \mathrm{Ag}_{x} \mathrm{~S}$ на основе $\mathrm{PbS}$ с металлической подрешеткой, легированной серебром. Максимальное относительное содержание серебра в твердых растворах $\mathrm{Pb}_{1-x} \mathrm{Ag}_{x} \mathrm{~S}$ доходит до $x=0.15$. Методом дилатометрии в области температур 295-580 K впервые измерено термическое расширение полупроводниковых твердых растворов $\mathrm{Pb}_{1-x} \mathrm{Ag}_{x} \mathrm{~S}$. Замещение атомов свинца атомами серебра в $\mathrm{Pb}_{1-x} \mathrm{Ag}_{x} \mathrm{~S}$ приводит к понижению коэффициента термического расширения, связанному с изменением ангармонизма атомных колебаний и слабым увеличением упругих свойств. Для монокристаллических частиц $\mathrm{PbS}$ и твердых растворов $\mathrm{Pb}_{1-x} \mathrm{Ag}_{x} \mathrm{~S}$ найдены пространственные распределения модуля упругости $E$, коэффициента Пуассона $\mu$ и линейной сжимаемости $\beta$ в зависимости от направления $(h k l)$. Измерены спектры отражения синтезированных порошков $\mathrm{PbS}, \mathrm{Ag}_{2} \mathrm{~S} \mathrm{~Pb}_{1-x} \mathrm{Ag}_{x} \mathrm{~S}$ и показано, что замещение свинца серебром в $\mathrm{PbS}$ сопровождается увеличением ширины запрещенной зоны.
\end{abstract}

Ключевые слова: твердые растворы, сульфиды свинца и серебра, термическое расширение, упругие и оптические своства.

DOI: $10.21883 /$ FTP.2019.12.48626.8988

\section{1. Введение}

Получение твердых растворов сульфидов, арсенидов и других полупроводников - один из способов регулирования свойств путем изменения состава. Узкозонный кубический сульфид свинца $\mathrm{PbS}$ с шириной запрещенной зоны $E_{g}=0.41-0.42$ эВ [1] и широкозонный моноклинный сульфид серебра $\mathrm{Ag}_{2} \mathrm{~S}$ с $E_{g}=0.89-0.91$ эВ [2] используются очень широко [3]. $\mathrm{PbS}$ применяется в фотодетекторах, термоэлектрических преобразователях, солнечных элементах и оптических переключателях, $\mathrm{Ag}_{2} \mathrm{~S}$ служит материалом для электронных и сенсорных устройств $[3,4]$. Получение твердых растворов $\mathrm{Pb}_{1-x} \mathrm{Ag}_{x} \mathrm{~S}$ сульфидов свинца и серебра увеличивает возможность регулирования их электронных и решеточных свойств. Из-за разных кристаллических структур $\mathrm{PbS}$ и $\mathrm{Ag}_{2} \mathrm{~S}$ их взаимная растворимость мала: по данным [5], повторенным в [6], предельная растворимость $\mathrm{Ag}_{2} \mathrm{~S}$ в $\mathrm{PbS}$ при $970 \mathrm{~K}$ не превышает 0.4 мол\%. Однако авторы [7] сумели получить твердые растворы $\mathrm{Pb}_{1-x} \mathrm{Ag}_{x} \mathrm{~S}$, в которых величина $x$ менялась от 0 до 0.16 . В работе [8] твердые растворы $\mathrm{Pb}_{1-x} \mathrm{Ag}_{x} \mathrm{~S}$ с $x$ до 0.025 получены вакуумным искровым плазменным спеканием (spark plasma sintering). Ограниченная растворимость $\mathrm{Ag}_{2} \mathrm{~S}$ в $\mathrm{PbS}$ позволяет говорить о легировании металлической подрешетки сульфида свинца серебром.

Сульфиды и сульфидные твердые растворы чаще всего используют в виде пленок на подложках, поэтому кроме электронных характеристик для их применения при повышенной температуре нужны данные о термическом расширении и упругих свойствах.
Согласно $[9,10]$, коэффициент термического расширения $\alpha$ поликристаллического $\mathrm{PbS}$ с кубической (пр.гр. $F m \overline{3} m)$ структурой типа $B 1$ при температуре $300 \mathrm{~K}$ равен $(19-20) \cdot 10^{-6} \mathrm{~K}^{-1}$, а по данным первопринципного расчета [11] при $300 \mathrm{~K} \alpha_{\mathrm{PbS}}=29.8 \cdot 10^{-6} \mathrm{~K}^{-1}$. Нанопленка $\mathrm{PbS}$ с кубической структурой типа $D 0_{3}$ при $393 \mathrm{~K}$ имеет коэффициент расширения $\sim 28 \cdot 10^{-6} \mathrm{~K}^{-1}$ [12]. По данным $[13,14]$, коэффициент линейного термического расширения нанопленки $\mathrm{PbS}$ при температуре от 323 до $473 \mathrm{~K}$ составляет $(37-39) \cdot 10^{-6} \mathrm{~K}^{-1}$.

Коэффициент термического расширения крупнокристаллического акантита $\alpha-\mathrm{Ag}_{2} \mathrm{~S}$ равен $\sim 20 \cdot 10^{-6} \mathrm{~K}^{-1}[15]$. Дилатометрические измерения теплового расширения крупнокристаллического сульфида серебра $[16,17]$ показали, что при температуре $293-455 \mathrm{~K}$, где существует акантит $\alpha-\mathrm{Ag}_{2} \mathrm{~S}$, коэффициент расширения $\alpha$ растет от $\sim 14 \cdot 10^{-6}$ до $\sim 19 \cdot 10^{-6} \mathrm{~K}^{-1}$, затем в области температуры превращения $\alpha-\mathrm{Ag}_{2} \mathrm{~S}-\beta-\mathrm{Ag}_{2} \mathrm{~S}$ наблюдается скачкообразное увеличение $\alpha$ до $\sim 29 \cdot 10^{-6} \mathrm{~K}^{-1}$. При температуре от $\sim 500$ до $\sim 800 \mathrm{~K}$ в области существования аргентита $\beta-\mathrm{Ag}_{2} \mathrm{~S}$ средний коэффициент расширения растет от $\sim 30 \cdot 10^{-6}$ до $\sim 42 \cdot 10^{-6} \mathrm{~K}^{-1}$. Коэффициент термического расширения нанокристаллического сульфида серебра в $\sim 1.3-1.4$ раза больше, чем $\alpha$ крупнокристаллического сульфида.

Сведений о термическом расширении, упругих свойствах и ширине запрещенной зоны твердых растворов $\mathrm{Pb}_{1-x} \mathrm{Ag}_{x} \mathrm{~S}$ в литературе нет. В связи с этим в данной работе впервые изучено термическое расширение $\mathrm{PbS}$ с металлической подрешеткой, легированной серебром, определены коэффициент термического расширения и 
модуль упругости твердых растворов $\mathrm{Pb}_{1-x} \mathrm{Ag}_{x} \mathrm{~S}$, измерены оптические спектры отражения.

\section{2. Образцы и экспериментальные методы}

Тонкодисперсные порошки сульфидов $\mathrm{PbS}$ и $\mathrm{Ag}_{2} \mathrm{~S}$ и сульфидных твердых растворов $\mathrm{Pb}_{1-x} \mathrm{Ag}_{x} \mathrm{~S}$ синтезировали методом химического осаждения. Порошок $\mathrm{PbS}$ осаждали по методике [3,18] из водных растворов ацетата свинца $\mathrm{Pb}\left(\mathrm{CH}_{3} \mathrm{COO}\right)_{2} \equiv \mathrm{Pb}(\mathrm{OAc})_{2}$ и сульфида натрия $\mathrm{Na}_{2} \mathrm{~S}$ в присутствии цитрата натрия $\mathrm{Na}_{3} \mathrm{C}_{6} \mathrm{H}_{5} \mathrm{O}_{7} \equiv \mathrm{Na}_{3} \mathrm{Cit}$ как стабилизатора дисперсности коллоидной системы, т.е. вещества, препятствующего агрегации коллоидных сульфидных частиц в более крупные и выпадению их в осадок. Концентрации реагентов в реакционной смеси были одинаковы и равны 0.05 моль $\cdot \pi^{-1}$.

Осаждение порошка $\mathrm{Ag}_{2} \mathrm{~S}$ проводили в темноте в нейтральной среде при $p H \approx 7$ из водных растворов $\mathrm{AgNO}_{3}$ и $\mathrm{Na}_{2} \mathrm{~S}$ в присутствии $\mathrm{Na}_{3} \mathrm{Cit}$ как стабилизатора по реакционной схеме, описанной ранее $[3,19,20]$. Осаждение проводили при избытке $\mathrm{Na}_{2} \mathrm{~S}$, необходимом для синтеза сульфида серебра без примеси частиц металлического Ag. Концентрации $\mathrm{AgNO}_{3}, \mathrm{Na}_{2} \mathrm{~S}$ и $\mathrm{Na}_{3} \mathrm{Cit}$ в реакционной смеси были равны $0.050,0.100$ и 0.025 моль $\cdot \pi^{-1}$ соответственно.

Порошки твердых растворов $\mathrm{Pb}_{1-x} \mathrm{Ag}_{x} \mathrm{~S}$ получали соосаждением $\mathrm{PbS}$ и $\mathrm{Ag}_{2} \mathrm{~S}$ из щелочных водных растворов ацетата свинца $\mathrm{Pb}(\mathrm{OAc})_{2}$, нитрата серебра $\mathrm{AgNO}_{3}$, тиокарбамида $\mathrm{N}_{2} \mathrm{H}_{4} \mathrm{CS}$ как сульфидизатора, гидроксида аммония $\mathrm{NH}_{4} \mathrm{OH}$ и цитрата натрия $\mathrm{Na}_{3} \mathrm{Cit}$ по методике [7]. С учетом комплексообразования соосаждение $\mathrm{PbS}$ и $\mathrm{Ag}_{2} \mathrm{~S}$ происходило по реакционным схемам

$$
\begin{aligned}
& \mathrm{Pb}(\mathrm{OH}) \mathrm{Cit}^{2-}+\mathrm{N}_{2} \mathrm{H}_{4} \mathrm{CS}+\mathrm{OH}^{-} \\
& =\mathrm{PbS} \downarrow+\mathrm{Cit}^{3-}+\mathrm{H}_{2} \mathrm{CN}_{2}+2 \mathrm{H}_{2} \mathrm{O}, \\
& 2\left[\mathrm{Ag}\left(\mathrm{N}_{2} \mathrm{H}_{4} \mathrm{CS}\right)_{3}\right]^{+}+2 \mathrm{OH}^{-} \\
& =\mathrm{Ag}_{2} \mathrm{~S} \downarrow+2 \mathrm{~N}_{2} \mathrm{H}_{4} \mathrm{CS}+\mathrm{H}_{2} \mathrm{CN}_{2}+2 \mathrm{H}_{2} \mathrm{O} .
\end{aligned}
$$

Во всех реакционных смесях концентрация $\mathrm{NH}_{4} \mathrm{OH}$ составляла 4 моль $\cdot л^{-1}$, концентрации тиокарбамида и цитрата натрия были равны 0.05 моль $\cdot \pi^{-1}$. Концентрации $\mathrm{Pb}(\mathrm{OAc})_{2}$ и $\mathrm{AgNO}_{3}$ в зависимости от состава синтезируемого твердого раствора меняли в интервалах $0.01-0.05$ и $0.001-0.015$ моль $\cdot л^{-1}$ соответственно. Попытка применить $\mathrm{Na}_{2} \mathrm{~S}$ как сульфидизатор оказалась неудачной из-за почти мгновенного осаждения сульфида $\mathrm{Ag}_{2} \mathrm{~S}$ вместо сульфидного твердого раствора $\mathrm{Pb}_{1-x} \mathrm{Ag}_{x} \mathrm{~S}$. Использование тиокарбамида позволило снизить скорость осаждения сульфида серебра благодаря образованию промежуточных комплексов $\left[\mathrm{Ag}\left(\mathrm{N}_{2} \mathrm{H}_{4} \mathrm{CS}\right)_{3}\right]^{+}$. Ocaждение твердых растворов проводили при $298 \mathrm{~K}$ и $\mathrm{pH}$ от 10 до 11 в течение 3 ч.

Структуру полученных порошков исследовали на рентгеновском дифрактометре Shimadzu XRD-7000 в
$\mathrm{Cu} K_{\alpha 1,2}$-излучении. Измерения проводили в интервале углов $2 \theta=20-85^{\circ}$ с шагом $\Delta(2 \theta)=0.02^{\circ}$ и временем сканирования 10 с в точке. Моделирование дифракционных данных и численный анализ рентгенограммы выполняли с помощью программного пакета X'Pert HighScore Plus [21].

Микроструктуру и элементный состав порошков изучали на сканирующем электронном микроскопе JEOL-JSM LA 6390 с анализатором JED 2300 Energy Dispersive $X$-ray Analyzer. Состав находили методом рентгеновского энергодисперсионного анализа EDX.

Коэффициент термического расширения измеряли на цилиндрических образцах диаметром 5 мм и длиной 4-6 мм, спрессованных под давлением $\sim 260$ МПа и спеченных в вакууме при температуре $\sim 470 \mathrm{~K}$ из синтезированных порошков сульфидов $\mathrm{PbS}$ и $\mathrm{Ag}_{2} \mathrm{~S}$ и однофазных твердых растворов $\mathrm{Pb}_{1-x} \mathrm{Ag}_{x} \mathrm{~S}$. Измерения проводили на дилатометре NETZSCH DIL 402C в атмосфере гелия Не при давлении $1.01 \cdot 10^{5}$ Па и изменении температуры от 293 до $573 \mathrm{~K}$ с шагом $0.5 \mathrm{~K}$ и скоростью нагрева $4 \mathrm{~K} \cdot$ мин $^{-1}$.

Оптические свойства порошков сульфидов и сульфидных твердых растворов измеряли на спектрофотометре Shimadzu UV-3600. Ширину запрещенной зоны $E_{g}$ определяли, используя оптические спектры отражения.

\section{3. Решеточные и оптические свойства}

По данным сканирующей электронной микроскопии (СЭМ), средний размер частиц в осажденных порошках $\mathrm{PbS}$ и $\mathrm{Ag}_{2} \mathrm{~S}$ равен примерно 100 и 800 нм, а в порошках $\mathrm{Pb}_{1-x} \mathrm{Ag}_{x} \mathrm{~S}$ составляет $\sim 300-500$ нм (рис. 1). Как пример определения элементного состава, на рис. 1 (см. вставку) показан EDX спектр твердого раствора $\mathrm{Pb}_{0.88} \mathrm{Ag}_{0.12} \mathrm{~S}$, в котором наряду с линиями $\mathrm{Pb}$ и $\mathrm{S}$ наблюдаются линии серебра Ag в области $\sim 2.9$ эВ. По данным

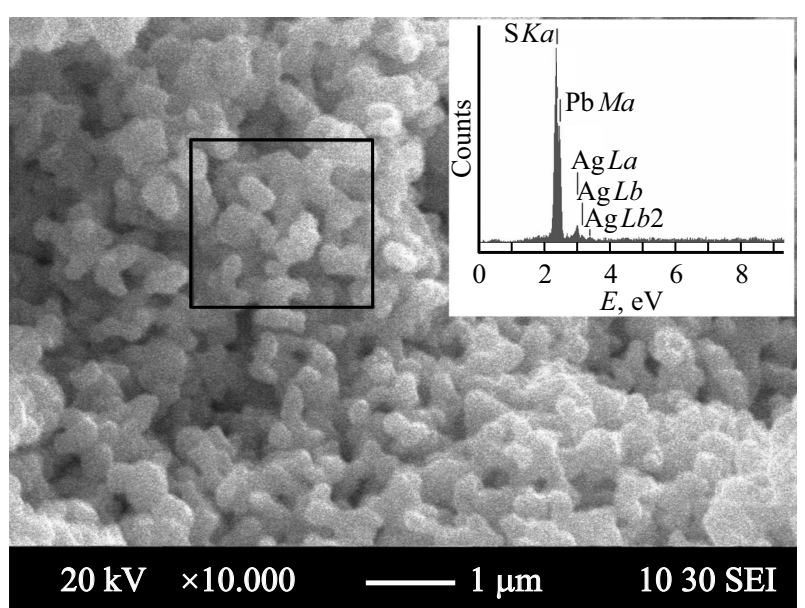

Рис. 1. СЭМ-изображение осажденного порошка $\mathrm{Pb}_{0.88} \mathrm{Ag}_{0.12} \mathrm{~S}$ с размером частиц 300-500 нм. На вставке показан элементный EDX-анализ порошка, полученный с области, выделенной прямоугольником. 


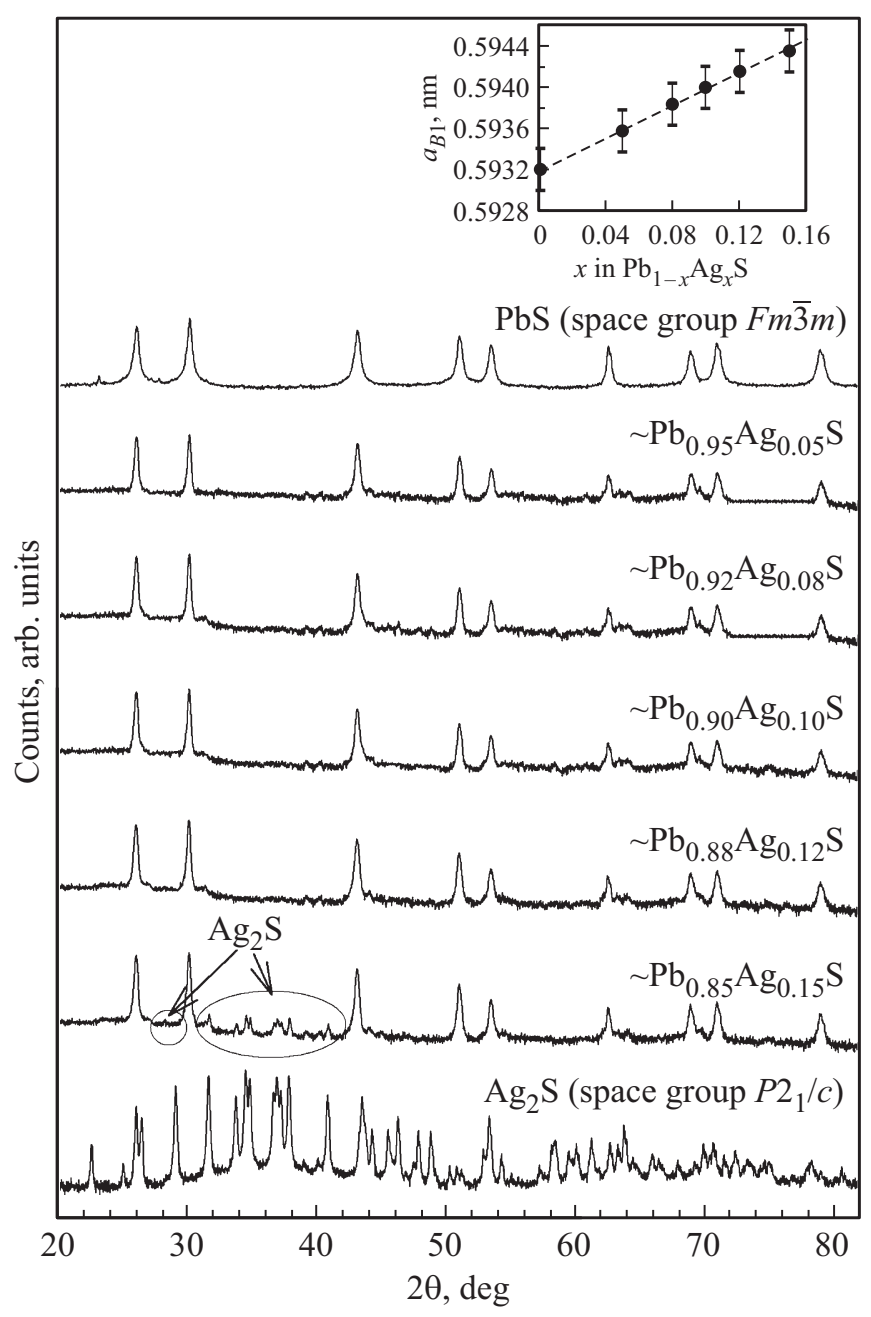

Рис. 2. Рентгенограммы сульфидов $\mathrm{PbS}$ и $\mathrm{Ag}_{2} \mathrm{~S}$ и ограниченных сульфидных твердых растворов $\mathrm{Pb}_{1-x} \mathrm{Ag}_{x} \mathrm{~S}(x<0.15)$. Твердые растворы с $0.05 \leq x \leq 0.12$ имеют кубическую (пр. гр. $F m \overline{3} m)$ структуру типа $B \overline{1}$ и являются однофазными. Твердый раствор $\mathrm{Pb}_{0.85} \mathrm{Ag}_{0.15} \mathrm{~S}$ наряду с основной кубической фазой содержит до 4-5 вес \% моноклинного (пр. гр. $P 2_{1} / c$ ) сульфида серебра $\mathrm{Ag}_{2} \mathrm{~S}$, чьи отражения на рентгенограмме выделены овалами и показаны стрелками. Интенсивность приведена в логарифмической шкале. На вставке показано изменение периода решетки твердых растворов $\mathrm{Pb}_{1-x} \mathrm{Ag}_{x} \mathrm{~S}$ при замещении атомов $\mathrm{Pb}$ атомами $\mathrm{Ag}$ (при увеличении $x$ от 0 до 0.15$)$.

EDX-анализа, содержание $\mathrm{Ag}, \mathrm{Pb}$ и $\mathrm{S}$ в $\mathrm{Pb}_{0.88} \mathrm{Ag}_{0.12} \mathrm{~S}$ равно $5.9 \pm 0.2,80.0 \pm 0.4$ и $13.1 \pm 0.5$ вес \% соответственно.

Рентгенограммы синтезированных порошков $\mathrm{PbS}$, $\mathrm{Ag}_{2} \mathrm{~S}$ и твердых растворов $\mathrm{Pb}_{1-x} \mathrm{Ag}_{x} \mathrm{~S}$ представлены на рис. 2. Порошок сульфида свинца $\mathrm{PbS}$ имеет кубическую (пр.гр. $F m \overline{3} m$ ) структуру типа $B 1$. Твердые растворы $\mathrm{Pb}_{1-x} \mathrm{Ag}_{x} \mathrm{~S}$ с $x \leq 0.12$ тоже являются кубическими и однофазными. Образец $\mathrm{Pb}_{0.85} \mathrm{Ag}_{0.15} \mathrm{~S}$ является двухфазным и наряду с основной кубической фазой содержит до 4-5 вес \% моноклинного сульфида серебра. Об образовании твердых растворов свидетельствуют смещение отражений в область меньших углов $2 \theta$, т.е. слабый рост периода $a_{B 1}$ кубической решетки при замещении свинца серебром (рис. 2, см. вставку). Моделирование дифракционных данных проводилось в программном пакете X'Pert HighScore Plus [21].

Твердые растворы $\mathrm{Pb}_{1-x} \mathrm{Ag}_{x} \mathrm{~S}$ сохраняют кубическую структуру сульфида $\mathrm{PbS}$, поэтому можно предположить, что в области ограниченной растворимости решетка сульфида серебра искажается до кубической. Объем элементарной ячейки моноклинного сульфида серебра при $273 \mathrm{~K}$ равен $0.2260 \mathrm{Hм}^{3}$ [3], поэтому период решетки модельной кубической элементарной ячейки с этим же объемом равен $a_{\mathrm{Ag}_{2} \mathrm{~S}}^{*}=0.6091$ нм. Если в первом приближении период $a_{s s}$ кубической решетки $\mathrm{PbS}$ при легировании серебром меняется линейно, то используя значения $a_{\mathrm{PbS}}=0.5932 \mathrm{нм}$ и $a_{\mathrm{As}_{2} \mathrm{~S}}^{*}=0.5996 \mathrm{нм}$, можно найти относительное содержание $\mathrm{Ag}_{2} \mathrm{~S}$ и $\mathrm{Ag}$ в твердом растворе как $z=\left(a_{s s}-a_{\mathrm{PbS}}\right) /\left(a_{\mathrm{Ag}_{2} \mathrm{~S}}^{*}-a_{\mathrm{PbS}}\right)$ и $x_{\mathrm{Ag}}=2 z$.

Полученные твердые растворы по оценкам, сделанным минимизацией рентгенограмм, с одной стороны, и по изменению периода решетки, с другой стороны, имеют состав $\sim \mathrm{Pb}_{0.95} \mathrm{Ag}_{0.05} \mathrm{~S}, \sim \mathrm{Pb}_{0.92} \mathrm{Ag}_{0.08} \mathrm{~S}$, $\sim \mathrm{Pb}_{0.90} \mathrm{Ag}_{0.10} \mathrm{~S}, \sim \mathrm{Pb}_{0.88} \mathrm{Ag}_{0.12} \mathrm{~S}$ и $\sim \mathrm{Pb}_{0.85} \mathrm{Ag}_{0.15} \mathrm{~S}$. Содержание $\mathrm{Ag}, \mathrm{Pb}$ и $\mathrm{S}$, определенное EDX-анализом, качественно согласуется с этими оценками.

Температурные зависимости среднего линейного коэффициента термического расширения $\alpha(T)$ образцов $\mathrm{PbS}$ и $\mathrm{Pb}_{1-x} \mathrm{Ag}_{x} \mathrm{~S}$ показаны на рис. 3. Коэффициенты $\alpha(T)$ сульфида $\mathrm{PbS}$ и твердых растворов $\mathrm{Pb}_{1-x} \mathrm{Ag}_{x} \mathrm{~S}$ в изученной области температур слабо увеличиваются с ростом $T$. Немного больший температурный рост $\alpha$ наблюдается для образца, содержащего твердый раствор $\mathrm{Pb}_{0.85} \mathrm{Ag}_{0.15} \mathrm{~S}$ с примесью сульфида серебра. Замещение атомов $\mathrm{Pb}$ в сульфиде свинца атомами $\mathrm{Ag}$ приводит к небольшому уменьшению коэффициентов термического расширения (рис. 3, см. вставку).

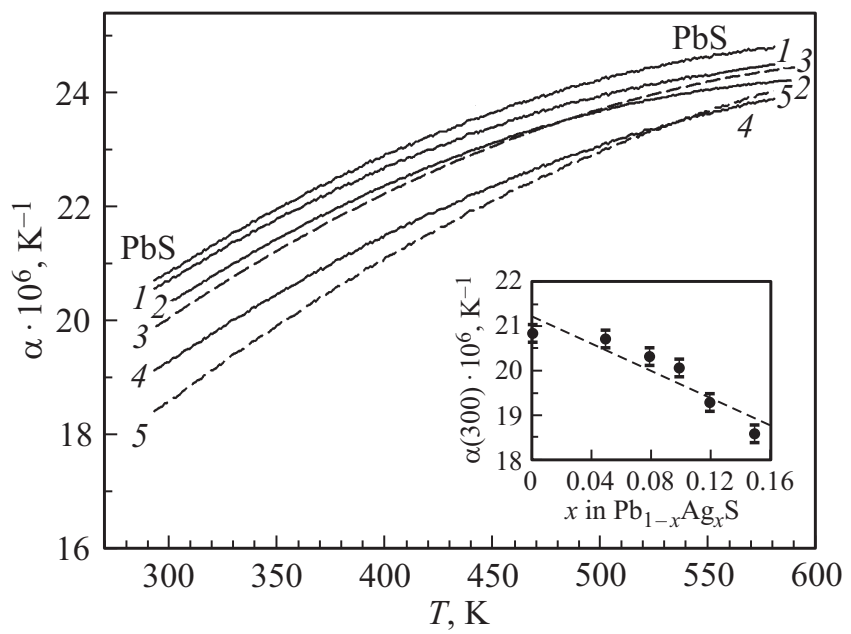

Рис. 3. Коэффициент термического расширения образцов $\mathrm{PbS}$ и $\mathrm{Pb}_{1-x} \mathrm{Ag}_{x} \mathrm{~S}$. $a-$ температурные зависимости $\alpha(T)$ : $x=0.05(1), 0.08$ (2), 0.10 (3), 0.12 (4), 0.15 (5). На вставке показано изменение $\alpha$ от состава $x$ твердых растворов при $300 \mathrm{~K}$. 

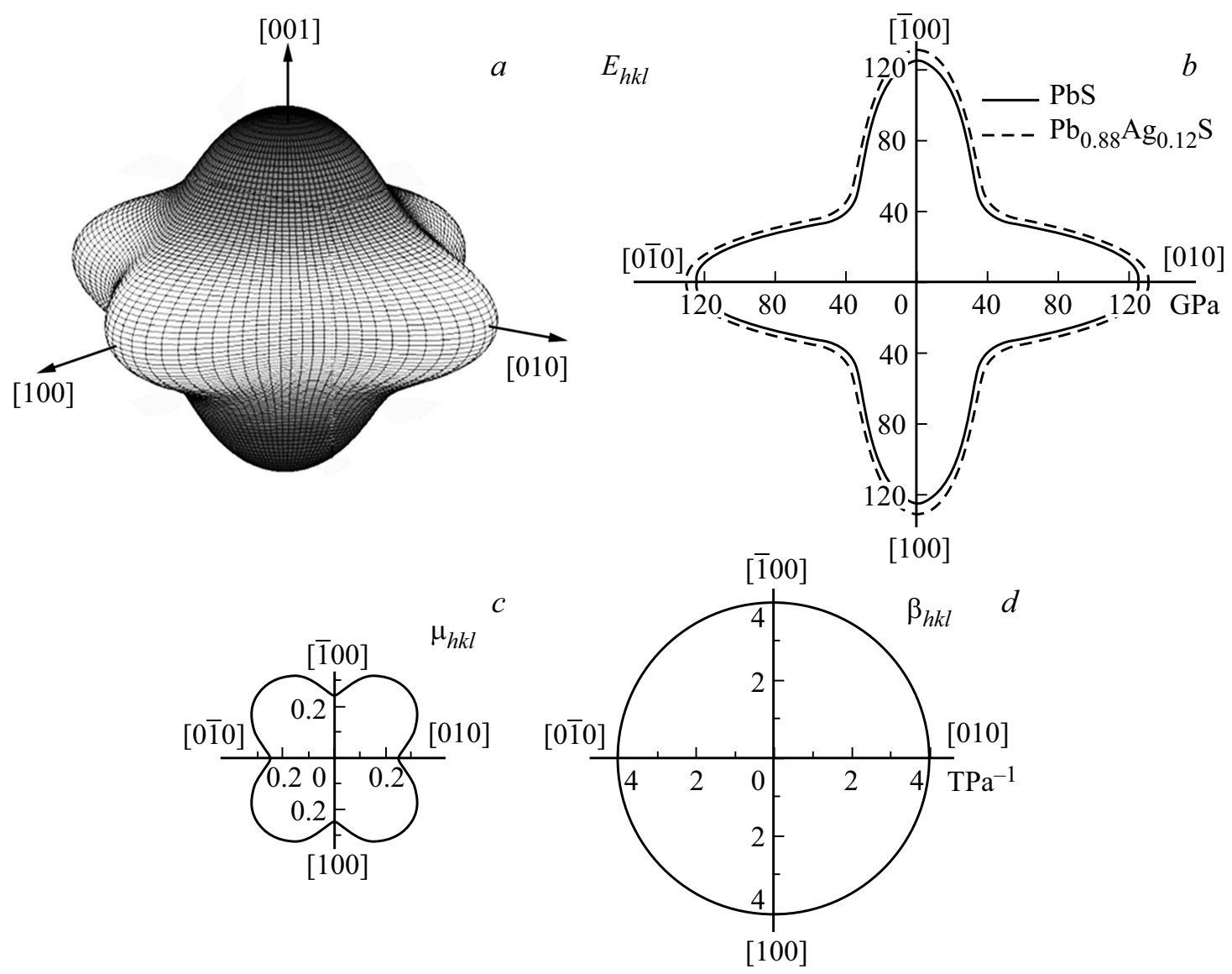

Рис. 4. Зависимости упругих характеристик монокристаллических частиц $\mathrm{PbS}$ (сплошная линия) и $\mathrm{Pb}_{0.88} \mathrm{Ag}_{0.12} \mathrm{~S}$ (пунктир) от кристаллографического направления $(h k l): a-$ пространственное распределение модуля упругости $E_{h k l}$ сульфида свинца; $b-$ распределения модулей упругости $E_{h k l}$ сульфида $\mathrm{PbS}$ и твердого раствора $\mathrm{Pb}_{0.88} \mathrm{Ag}_{0.12} \mathrm{~S}$ в плоскости $(h k 0) ; c, d-$ распределения коэффициента Пуассона $\mu_{h k l}$ и линейной сжимаемости $\beta_{h k l}$ в плоскости $(h k 0)$. Распределения $E_{h k l}, \mu_{h k l}$ и $\beta_{h k l}$ в плоскостях (h01) и $(0 \mathrm{kl})$ имеют такой же вид.

Термическое расширение твердого тела обусловлено ангармонизмом атомных колебаний. С одной стороны, линейный коэффициент термического расширения имеет вид

$$
\alpha(T)=\left(1 / a_{293 \mathrm{~K}}\right) d\langle u\rangle / d T=k_{\mathrm{B}} \beta /\left(A_{h}^{2} a_{293 \mathrm{~K}}\right),
$$

где $a_{293 \mathrm{~K}}-$ период решетки, $\langle u\rangle-$ среднее по времени отклонение атома от положения равновесия, $\beta-$ коэффициент ангармонизма колебаний атомов, $A_{h}-$ постоянная, учитывающая вклад гармонических колебаний в потенциальную энергию кристалла. Тепловое расширение или сжатие можно объяснить только при учете ангармонизма атомных колебаний, т. е. при $\beta \neq 0$, так как в гармоническом приближении, когда $\beta=0$, коэффициент линейного расширения равен 0 и тепловое расширение отсутствует. Из (2) ясно, что наблюдаемое уменьшение коэффициента термического расширения $\alpha$ при замещении в сульфиде свинца атомов $\mathrm{Pb}$ атомами $\mathrm{Ag}$ может быть обусловлено ростом периода решетки, с одной стороны, и уменьшением ангармонизма атомных колебаний, с другой стороны. При увеличении $x$ от 0 до 0.15 период $a_{B 1}$ твердых растворов вырос от 0.5932 до 0.5937 нм, однако такое увеличение периода недостаточно для уменьшения $\alpha(300)$ от $20.8 \cdot 10^{-6}$ до $18.6 \cdot 10^{-6} \mathrm{~K}^{-1}$. Если коэффициент $A_{h}$ при замещении свинца серебром остается постоянным, то наблюдаемое с ростом $x$ снижение $\alpha$ твердых растворов $\mathrm{Pb}_{1-x} \mathrm{Ag}_{x} \mathrm{~S}$ обусловлено в основном уменьшением ангармонизма колебаний атомов. Действительно, в работе [8] отмечено, что замещение свинца в $\mathrm{PbS}$ серебром приводит к уменьшению ангармонизма решетки и(или) увеличению скорости фононов.

С другой стороны, линейный коэффициент термического расширения $\alpha(T)$ связан с удельной теплоемкостью $C_{s p}=C_{V} / v_{m}$, отнесенной к единице объема вещества, соотношением

$$
\alpha(T)=\gamma C_{s p}(T) / 3 B \equiv \frac{\gamma}{3 B} \frac{C_{V}(T)}{v_{m}},
$$

где $\gamma-$ постоянная Грюнайзена, $B-$ модуль всестороннего сжатия, $v_{m}-$ молярный объем. Сделанная оценка показала, что $\gamma, C_{V}$ и $v_{m}$ почти не зависят от состава $\mathrm{Pb}_{1-x} \mathrm{Ag}_{x} \mathrm{~S}$ в узкой области $0<x<0.15$, поэтому из (3) следует, что уменьшение коэффициента 
расширения $\alpha(300)$ твердых растворов при увеличении $x$ связано с небольшим ростом модуля всестороннего сжатия $B=\left(c_{11}+2 c_{12}\right) / 3$ [22,23] и упругих постоянных $c_{11}$ и $c_{12}$.

Осажденные микрочастицы сульфида $\mathrm{PbS}$ и твердых растворов $\mathrm{Pb}_{1-x} \mathrm{Ag}_{x} \mathrm{~S}$ являются монокристаллическими. Ранее в работах $[14,24]$ для монокристаллических частиц $\mathrm{PbS}$ с использованием данных [24] о скоростях распространения ультразвука в направлениях [100] и [110] монокристалла $\mathrm{PbS}$ было найдено, что при $300 \mathrm{~K}$ компоненты тензора упругих деформаций $s_{11}, s_{12}$ и $s_{44}$ равны $8.01 \cdot 10^{-12},-2.0 \cdot 10^{-12}$ и $59.3 \cdot 10^{-12}\left[\mathrm{M}^{2} / \mathrm{H}\right]$. Близость измеренных температурных зависимостей $\alpha(T)$ твердых растворов $\mathrm{Pb}_{1-x} \mathrm{Ag}_{x} \mathrm{~S}$ и сульфида $\mathrm{PbS}$ и одинаковая кубическая структура означают, что $\mathrm{PbS}$ и твердые растворы имеют близкие и подобные температурные зависимости упругих модулей и величин $s_{11}, s_{12}$ и $s_{44}$. Согласно выполненной оценке, для монокристаллических частиц твердого раствора $\mathrm{Pb}_{0.88} \mathrm{Ag}_{0.12} \mathrm{~S}$ компоненты $s_{11}=7.69 \cdot 10^{-12}$, $s_{12}=-1.92 \cdot 10^{-12}$ и $s_{44}=56.7 \cdot 10^{-12}\left[\mathrm{~m}^{2} / \mathrm{H}\right]$. Используя данные по $s_{11}, s_{12}$ и $s_{44}$ для монокристаллических частиц $\mathrm{PbS}$ и $\mathrm{Pb}_{0.88} \mathrm{Ag}_{0.12} \mathrm{~S}$, можно в соответствии с [25] найти зависимости модуля упругости $E$ и коэффициента Пуассона $\mu$ от направления $(h k l)$ :

$$
\begin{gathered}
E_{h k l}=\frac{1}{s_{11}-2\left(s_{11}-s_{12}-\frac{1}{2} s_{44}\right) \Gamma}, \\
\mu_{h k l}=\frac{1}{2}-\frac{E_{h k l}\left(s_{11}^{2}+s_{11} s_{12}-2 s_{12}^{2}\right)}{2\left(s_{11}-s_{12}\right)},
\end{gathered}
$$

где

$$
\Gamma=\frac{h^{2} k^{2}+h^{2} l^{2}+k^{2} l^{2}}{\left(h^{2}+k^{2}+l^{2}\right)^{2}} .
$$

Рассчитанные зависимости упругих характеристик монокристаллических частиц $\mathrm{PbS}$ и $\mathrm{Pb}_{0.88} \mathrm{Ag}_{0.12} \mathrm{~S}$ от направления $(h k l)$ показаны на рис. 4. Пространственное распределение модуля упругости $E_{h k l}$ сульфида свинца (рис. 4, $a$ ) симметрично относительно плоскостей $(h k 0)$, $(h 0 l)$ и $(0 k l)$. Распределения модулей упругости $E_{h k l}$ сульфида $\mathrm{PbS}$ и твердого раствора $\mathrm{Pb}_{0.88} \mathrm{Ag}_{0.12} \mathrm{~S}$ в плоскости $(h k 0)$ показаны на рис. $4, b$. Частичное замещение атомов $\mathrm{Pb}$ в $\mathrm{PbS}$ атомами $\mathrm{Ag}$ приводит к небольшому росту модуля упругости $E$ : максимальное и минимальное значения $E$ для $\mathrm{PbS}$ равны 124.8 и 56.1ГПа, а для $\mathrm{Pb}_{0.88} \mathrm{Ag}_{0.12} \mathrm{~S}$ - 128.4 и 58.4 ГПа. Распределения коэффициента Пуассона $\mu_{h k l}$ и линейной сжимаемости $\beta_{h k l}$ в плоскости $(h k 0)$ показаны на рис. 4,c,d. Частичное замещение атомов $\mathrm{Pb}$ в $\mathrm{PbS}$ атомами $\mathrm{Ag}$ почти не влияет на $\mu_{h k l}$ и $\beta_{h k l}$, изменения которых при увеличении $x$ от 0 до 0.12 лежат в пределах ошибки определения. Величина $\beta_{h k l}=\left(s_{11}+2 s_{12}\right)$ в любом направлении равна $4.01 \cdot 10^{-12} \Pi^{-1}=4.01(\mathrm{T \Pi а})^{-1}$.

В работе [26] описан ab initio метод расчета упругих констант неорганических материалов. Результаты расчетов по упругим свойствам $\mathrm{PbS}$ и $\mathrm{Ag}_{2} \mathrm{~S}$ в виде баз данных представлены на сайтах [27,28]. По данным [27],

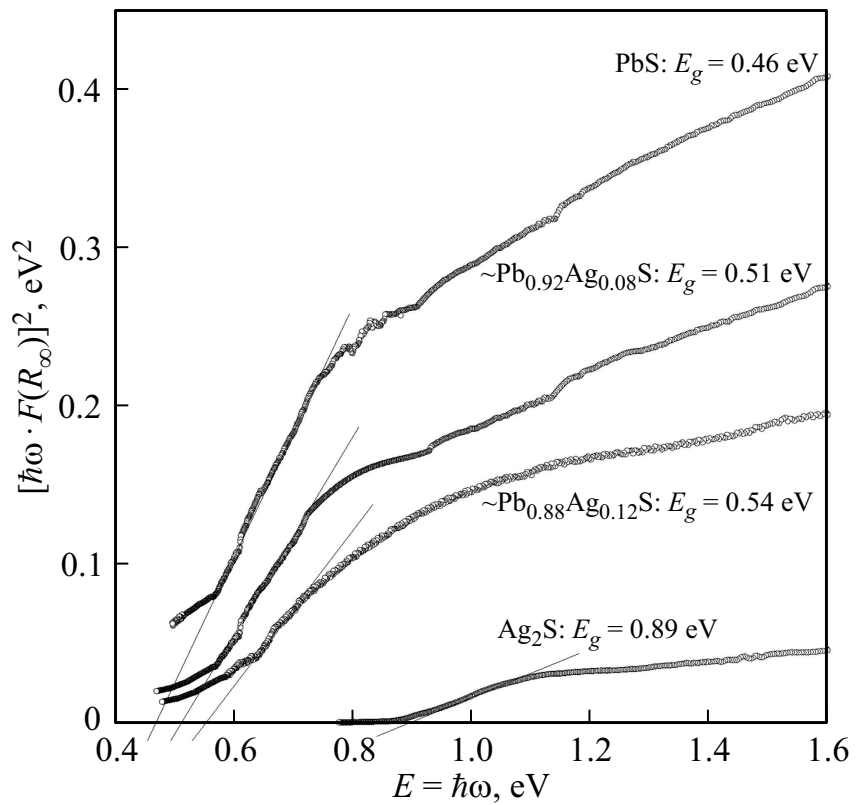

Рис. 5. Зависимости $\left[\hbar \omega F\left(R_{\infty}\right)\right]^{2}$ от энергии фотонов $\hbar \omega$ и ширина запрещенной зоны $E_{g}$ для порошков $\mathrm{PbS}$ и $\mathrm{Ag}_{2} \mathrm{~S}$ и твердых растворов $\mathrm{Pb}_{0.92} \mathrm{Ag}_{0.08} \mathrm{~S}$ и $\mathrm{Pb}_{0.88} \mathrm{Ag}_{0.12} \mathrm{~S}$.

модуль упругости $E$ сульфида свинца в зависимости от направления $(h k l)$ меняется от $\sim 53$ до $\sim 116$ ГПа. Согласно расчету [29] методом молекулярной динамики, усредненный модуль упругости $E$ сульфида свинца составляет $\sim 75$ ГПа. Полученные результаты по $E_{h k l}$ сульфида свинца (рис. 4) близки к данным [27,29].

Ширину запрещенной зоны $E_{g}$ порошков сульфидов и сульфидных твердых растворов определяли по краю полосы поглощения, преобразуя оптические спектры отражения. Для оценки ширины запрещенной зоны прямых переходов использовали функцию Кубелки-Мунка [30]

$$
\left[\hbar \omega F\left(R_{\infty}\right)\right]^{2}=A\left(\hbar \omega-E_{g}\right),
$$

где $\omega=2 \pi c / \lambda-$ частота излучения, $E=\hbar \omega=2 \pi \hbar c / \lambda$ $=h c / \lambda-$ энергия фотона. Функция $F\left(R_{\infty}\right)=(1-R)^{2} / 2 R$ определяется из коэффициента отражения $R$, измеренного в относительных единицах.

В реальном эксперименте полоса поглощения размыта и поэтому зависимость $\left[\hbar \omega F\left(R_{\infty}\right)\right]^{2}=f(\hbar \omega)$ вблизи края полосы является нелинейной. В этом случае ширина щели $E_{g}$ определяется величиной отрезка, отсекаемого на оси $\hbar \omega$ касательной к линейной части экспериментальной кривой $\left[\hbar \omega F\left(R_{\infty}\right)\right]^{2}=f(\hbar \omega)$.

На рис. 5, как пример, показаны спектры отражения порошков сульфидов $\mathrm{PbS}$ и $\mathrm{Ag}_{2} \mathrm{~S}$ и твердых растворов $\mathrm{Pb}_{0.92} \mathrm{Ag}_{0.08} \mathrm{~S}$ и $\mathrm{Pb}_{0.88} \mathrm{Ag}_{0.12} \mathrm{~S}$, построенные в координатах $\left[\hbar \omega F\left(R_{\infty}\right)\right]^{2} \leftrightarrow \hbar \omega$. Во всех спектрах край полосы поглощения размыт в области низких энергий. Количественная минимизация экспериментальных данных по коэффициенту отражения $R$ порошков функцией (5) позволила определить для них величины $E_{g}$. Минимизацию проводили на почти линейном участке зависимости $\left[\hbar \omega F\left(R_{\infty}\right)\right]^{2}=f(\hbar \omega)$. Расчет показал, что ширина 
щели $E_{g}$ для порошков $\mathrm{PbS}, \mathrm{Pb}_{0.92} \mathrm{Ag}_{0.08} \mathrm{~S}, \mathrm{~Pb}_{0.88} \mathrm{Ag}_{0.12} \mathrm{~S}$ и $\mathrm{Ag}_{2} \mathrm{~S}$ равна $\sim 0.46, \sim 0.51, \sim 0.54$ и $\sim 0.89$ эВ. Для $\mathrm{PbS}$ и $\mathrm{Ag}_{2} \mathrm{~S}$ найденные величины $E_{g}$ в пределах ошибок измерений совпадают с литературными данными для крупнокристаллических сульфидов свинца и серебра [1,2]. Полученные результаты по решеточным свойствам суульфидных твердых растворов согласуются с данными работ [31-34].

\section{4. Заключение}

Легирование металлической подрешетки сульфида $\mathrm{PbS}$ серебром и замещение атомов $\mathrm{Pb}$ атомами $\mathrm{Ag}$ в твердых растворах $\mathrm{Pb}_{1-x} \mathrm{Ag}_{x} \mathrm{~S}(x \leq 0.15)$ сопровождается незначительным ростом периода кубической решетки, снижением коэффициента термического расширения твердых растворов, обусловленным уменьшением энгармонизма атомных колебаний и слабым увеличением упругих свойств, а также увеличением ширины запрещенной зоны от 0.46 до 0.54 эВ при изменении $x$ от 0 до 0.12 .

\section{Благодарности}

Автор благодарит Д.А. Ягодина за помощь в дилатометрических измерениях и А.И. Гусева за полезное обсуждение.

\section{Конфликт интересов}

Автор заявляет, что у него нет конфликта интересов.

\section{Список литературы}

[1] R.B. Schoolar, J.R. Dixon. Phys. Rev., 137 (2A), 667 (1965).

[2] P. Junod. Helv. Phys. Acta, 32 (6-7), 567 (1959).

[3] S.I. Sadovnikov, A.A. Rempel, A.I. Gusev. Nanostructured Lead, Cadmium and Silver Sulfides: Structure, Nonstoichiometry and Properties (Cham-Heidelberg-N. Y.-DordrechtLondon, Springer Intern. Publ. AG, 2018) 331 pp.

[4] S.I. Sadovnikov, A.I. Gusev. J. Mater. Chem. A, 5 (34), 17676 (2017).

[5] H.J. Van Hook. Econ. Geol., 55 (4), 759 (1960).

[6] Л.Е. Шелимова, В.Н. Томашик, В И. Грицив. Диаграммы состояния в полупроводниковом материаловедении (М., Наука, 1991) с. 255.

[7] Л.Н. Маскаева, В.Ф. Марков, Т.В. Виноградова, А.А. Ремпель, А.И. Гусев. Поверхность. Рентгеновские, синхронные и нейтронные исследования, 9, 35 (2003).

[8] Y. Zheng, S. Wang, W. Liu, Z. Yin, H. Li, X. Tang, C. Uher. J. Phys. D: Appl. Phys., 47 (11), 115303 (2014).

[9] S.S. Sharma. Proc. Indian Acad. Sci. Sect. A, 34 (2), 72 (1951).

[10] С.И. Новикова, Н.Х. Абрикосов. ФТТ, 5 (7), 1913 (1963).

[11] Yi Zhang, X. Ke, C. Chen, J. Yang, P.R.C. Kent. Phys. Rev. B, 80 (2), 024304 (2009).

[12] С.И. Садовников, А.А. Ремпель. ФТТ, 51 (11), 2237 (2009).

[13] S.I. Sadovnikov, N.S. Kozhevnikova, A.A. Rempel, A. Magerl. Thin Sol. Films, 548, 230 (2013).

[14] S.I. Sadovnikov, A.I. Gusev. J. Alloys Comp., 610, 196 (2014).

[15] H. Okazaki, A. Takano. Ztsch. Naturforsch. A, 40 (10), 986 (1985).
[16] С.И. Садовников, А.И. Гусев. ФТТ, 59 (9), 1863 (2017).

[17] A.I. Gusev, S.I. Sadovnikov. Thermochim. Acta, 660, 1 (2018).

[18] S.I. Sadovnikov, A.I. Gusev. J. Alloys Comp., 586, 105 (2014).

[19] С.И. Садовников, А.А. Ремпель. Неорг. матер., 51 (8), 829 (2015).

[20] S.I. Sadovnikov, A.A. Rempel, A.I. Gusev. Russ. Chem. Rev., 87 (4), 303 (2018).

[21] X'Pert HighScore Plus. Version 2.2e (2.2.5). (c) 2009 PANalytical B.V. Almedo, the Netherlands.

[22] G.A. Alers. In: Lattice Dynamics (Physical Acoustics. Principles and Methods v. III, Pt B, Chap. 1) [Ed. by W.P. Mason (N.Y.-London, Academic Press, 1965)] p. 12.

[23] G. Leibfried. Gittertheorie der Mechanischen und Thermischen Eigenschaften der Kristalle (Handbuch der Physik, Bd. VII. Teil 2. Berlin, Springer Verlag, 1955).

[24] А.А. Чудинов. ФТТ, 5 (5), 1458 (1963).

[25] T. Gnäupel-Herold, P.C. Brand, H.J. Prask. (In: Advances in $X$-ray analysis, v. 42, ICDD, 1998).

[26] R. Gaillac, P. Pullumbi, F.-X. Coudert. J. Phys.: Condens. Matter, 28 (27), 275201 (2016).

[27] http://progs.coudert.name/elate/mp?query $=m p-21276$

[28] http://progs.coudert.name/elate/mp?query $=\mathrm{mp}-610517$

[29] T. Seetawan, H. Wattanasarn. Proc. Eng., 32, 609 (2012).

[30] P. Kubelka, F. Munk. Zeitschr. Techn. Physik, № 11a, 593 (1931).

[31] S.I. Sadovnikov, A.I. Gusev. J. Therm. Anal. Calor. 131 (2), 1155 (2018).

[32] S.I. Sadovnikov, E.G. Vovkotrub, A.A. Rempel. Doklady Phys. Chem. 480 (2), 80 (2018).

[33] S.I. Sadovnikov. J. Alloys Comp. 788, 586 (2019).

[34] S.I. Sadovnikov. Intern. J. Nanoscience 18 (3-4), 1940061 (2019). 3 pp.

Редактор Г.А. Оганесян

\section{The effects of doping of lead sulfide by silver on the lattice and optical properties of solid solutions $\mathbf{P b}_{1-x} \mathbf{A g}_{x} \mathbf{S}$}

\section{S.I. Sadovnikov}

Institute of Solid State Chemistry, Ural Branch of the Russian Academy of Sciences, 620990 Ekaterinburg, Russia

Abstract Single-phase limited cubic solid solutions $\mathrm{Pb}_{1-x} \mathrm{Ag}_{x} \mathrm{~S}$ based on $\mathrm{PbS}$ with a metal sublattice alloyed with silver are obtained. The maximum relative content of silver in solid solutions $\mathrm{Pb}_{1-x} \mathrm{Ag}_{x} \mathrm{~S}$ reaches $x=0.15$. For the first time the thermal expansion of semiconductor solid solutions $\mathrm{Pb}_{1-x} \mathrm{Ag}_{x} \mathrm{~S}$ was measured by dilatometry method in the temperature range $295-580 \mathrm{~K}$. Substitution of lead atoms by silver atoms in $\mathrm{Pb}_{1-x} \mathrm{Ag}_{x} \mathrm{~S}$ leads to a decrease in the coefficient of thermal expansion associated with a change in the anharmonicity of atomic vibrations and a weak increase in the elastic properties. For single-crystal particles $\mathrm{PbS}$ and solid solutions $\mathrm{Pb}_{1-x} \mathrm{Ag}_{x} \mathrm{~S}$, spatial distributions of the elastic modulus $E$, Poisson's ratio $\mu$, and linear compressibility $\beta_{h k l}$ as a function of the direction $(h k l)$ are found. The reflection spectra of the synthesized powders $\mathrm{PbS}, \mathrm{Ag}_{2} \mathrm{~S}$ and $\mathrm{Pb}_{1-x} \mathrm{Ag}_{x} \mathrm{~S}$ are measured and it is shown that the replacement of lead with silver in $\mathrm{PbS}$ is accompanied by an increase in the width of the band gap. 